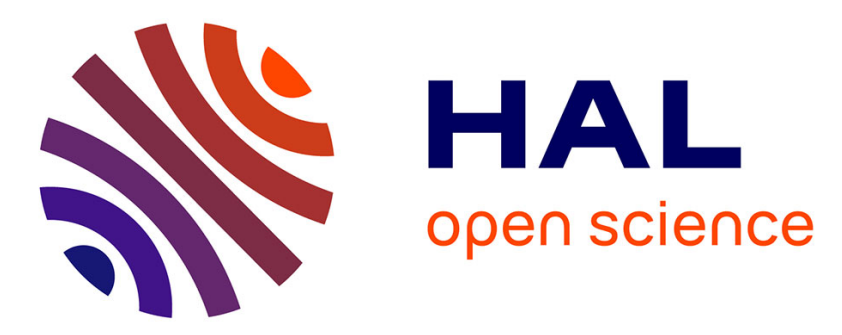

\title{
An investigation of dielectric barrier discharge in Ar and Ar/NH3 mixture using cross-correlation spectroscopy
}

\author{
P Kloc, H-E Wagner, D Trunec, Z Navrátil, G Fedoseev
}

\section{To cite this version:}

P Kloc, H-E Wagner, D Trunec, Z Navrátil, G Fedoseev. An investigation of dielectric barrier discharge in Ar and Ar/NH3 mixture using cross-correlation spectroscopy. Journal of Physics D: Applied Physics, 2010, 43 (34), pp.345205. 10.1088/0022-3727/43/34/345205 . hal-00569685

\section{HAL Id: hal-00569685 \\ https://hal.science/hal-00569685}

Submitted on 25 Feb 2011

HAL is a multi-disciplinary open access archive for the deposit and dissemination of scientific research documents, whether they are published or not. The documents may come from teaching and research institutions in France or abroad, or from public or private research centers.
L'archive ouverte pluridisciplinaire HAL, est destinée au dépôt et à la diffusion de documents scientifiques de niveau recherche, publiés ou non, émanant des établissements d'enseignement et de recherche français ou étrangers, des laboratoires publics ou privés. 


\title{
Investigation of dielectric barrier discharge in Ar and $\mathrm{Ar} / \mathrm{NH}_{3}$ mixture using cross-correlation spectroscopy
}

\author{
P Kloc ${ }^{1}$, H-E Wagner ${ }^{2}$, D Trunec ${ }^{1}$, Z Navrátil $^{1}$ and G Fedoseev ${ }^{3}$ \\ ${ }^{1}$ Department of Physical Electronics, Faculty of Science, Masaryk University, \\ Kotlářská 2, 61137 Brno, Czech Republic \\ ${ }^{2}$ Institute of Physics, University of Greifswald, F.-Hausdorff-Str 6., 17489 \\ Greifswald, Germany \\ ${ }^{3}$ Department of Material Science, Moscow State University of Design and \\ Technology, Sadovnicheskaya str. 33, 117997 Moscow, Russia \\ E-mail: kloc@physics.muni.cz
}

\begin{abstract}
Dielectric barrier discharges (BDs) are known to operate in two distinctive modes. Filamentary mode of DB is characterized by large number of short lasting spatially bounded microdischarges. This type of discharge is typical for most cases of $\mathrm{BDs}$ at atmospheric pressure. Under some specific conditions another form of BD may arise. In this mode plasma covers uniformly the whole electrode area. This mode is usually referred to as diffuse or homogeneous mode of BD.

This work presents studies of filamentary mode of BD in argon and its transition to the diffuse mode by ammonia addition. The discharges were investigated by the means of Cross Correlation Spectroscopy (CCS). Particularly the influence of electrode shape, discharge gap and influence of ammonia admixture on discharge development were studied. The measurement offers results with high temporal and spatial resolution which are useful for comparison with results of numerical models.

The obtained results include the electrical current measurement of discharge in several ammonia admixtures to argon. The diffuse discharge appeared at ammonia admixture above $3 \mathrm{vol} \%$ The observed propagation of streamer in discharge in pure argon for two different electrode configuration is presented. When compared to discharge in pure argon the streamer velocity is decreased for $0.1 \mathrm{vol} \%$ ammonia admixture. With increasing ammonia concentration the streamer velocity increases again. The behaviour of presented impurities was observed and the results are included in this report. The basic model of the discharge kinetic is included. For reduced electric field below $10 \mathrm{Td}$ the electron drift is much higher in argon ammonia mixture than in pure argon.
\end{abstract}

PACS numbers: 52.77.Fv, 52.70.-m

Submitted to: J. Phys. D: Appl. Phys. 


\section{Introduction}

The plasma in dielectric barrier discharge $(\mathrm{BD})$ is a non-thermal low temperature plasma. Usually BDs appear in form of many microdischarges of nanoseconds to microseconds durations [1]. The properties of one filament (microdicharge) are determined mainly by the used gas, but they can be also influenced by the electrodes as it is shown later in this paper. The typical filament in synthetic air at atmospheric pressure has diameters of roughly $0.1 \mathrm{~mm}$ at the middle of discharge gap. This diameter stretches close to electrodes where the covered area diameter can be of the order of magnitude larger. The duration of microdischarge is in the order of nanoseconds.

The development of one microdischarge is driven by the streamer mechanism due to the formation of high concentration of charged particles. The microdischarge is formed when both electrodes are connected by streamer. The buildup of charge on the surface of dielectrics reduces effectively electric field in the filament area thus effectively terminating the microdicharge. The charge transported by one microdischarge is small, just in order of $\mathrm{nC}$ [2]. Due to short duration of microdischarge the heating up of surrounding area is negligible and the temperature of neutral particles is close to room temperature.

At some specific conditions (electrode configuration, applied voltage, gas) another form of dielectric barrier discharge may appear. This type of discharge does not form filaments but uniformly covers whole electrode area. Since appearance of this discharge type is more diffused it is often referred to as diffuse dielectric barrier discharge or homogeneous dielectric barrier discharge. More mechanisms leading to transition from filamentary BD to diffuse barrier discharge exist. Recent progress in understanding of the diffuse discharges was summarized in [3].

The BD was investigated in many different gases. The study of diffuse BD in nitrogen and its transition to the filamentary mode after oxygen admixture was presented in [4] and [5]. The diffuse barrier discharge in neon and helium was investigated in e.g. $[6,7,8]$.

A method of Cross Correlation Spectroscopy (CCS) is suitable for the micodischarge investigation. This technique provides temporal and spatial resolution of light emission at selected wavelength. The time resolution of CCS is in order of tenths of nanoseconds. The spatial resolution is determined by quality of optical system and it is usually in order of micrometers. Such good temporal resolution can be hardly achieved by any other method. We decided to use this technique for our measurements because filamentary discharges have generally very short duration.

The comparison of discharge in neon and argon using CCS was presented in [9]. The difference in discharge characteristics was clearly visible. While discharges in pure neon and helium can burn in diffuse form, no such behaviour was observed in case of pure argon. However it was reported in [10] that admixture of ammonia to argon can also lead to diffuse mode. This diffuse discharge in the mixture of argon and ammonia could be used for thin film deposition, especially for deposition of $\mathrm{Si}_{3} \mathrm{~N}_{4}$ films from suitable 
Table 1. Summary of electrodes parameters.

\begin{tabular}{llll}
\hline Electrodes shape & gap width $(\mathrm{mm})$ & dielectric material & $\epsilon_{r}$ \\
\hline Planar & 1.1 & glass & 4 \\
Semispherical & 1.0 & alumina oxide & 9 \\
Cylindrical & 2.0 & MACOR & 6 \\
\hline
\end{tabular}

monomer [11].

In this article we focused on thorough investigation of discharge in pure argon and in argon with admixture of ammonia. The results reported by Kozlov et al in [9] had low resolution, so it was not possible to observe the beginning phase of the discharge in detail. The measurement was also done with only one set of electrodes. In this work we studied the influence of different electrode shapes on discharge in argon. The influence of discharge gap was also studied. In our investigation we were mainly using CCS technique but other diagnostic methods were also used. The second goal of our study was to evaluate the influence of ammonia on the development of discharge in argon/ammonia mixtures.

\section{Experimental setup}

The experimental setup is consistent with setup used for CCS described in [12]. The schema of the setup is shown in figure 1. The discharge was generated between two electrodes covered with dielectric layer. Three different electrode configurations were used during experiments. Cross section of electrodes is shown in figure 2. Electrodes characteristic is summarized in table 1 . The metal parts of electrodes were made of steel in all cases. The first electrode configuration was a planar configuration. The metal electrodes with area $20 \mathrm{~mm} \times 20 \mathrm{~mm}$ were fastened inside organic glass holder. The metal electrodes were covered with $2.1 \mathrm{~mm}$ thick glass $\left(\epsilon_{r} \doteq 4\right)$. Discharge gap width was fixed at $1.1 \mathrm{~mm}$ with two organic glass holders. This electrode configuration could not be used for CCS since the microdischarges were not spatially stable. It could however provide information on the type of discharge.

The second electrode configuration consisted of metal rod covered with $1 \mathrm{~mm}$ alumina oxide layer $\left(\epsilon_{r} \doteq 9\right)$. The tip of both electrode and rod had spherical shape. This configuration ensures spatially stable microdischage. The disadvantage of this electrode configuration was the occurrence of long surface discharges running along the electrode. This phenomenon was not observed in case of planar electrode configuration.

The last electrode configuration was cylindrical with total diameter of $1.5 \mathrm{~cm}$. These electrodes were made of $1 \mathrm{~mm}$ diameter metal rod covered with ceramics called MACOR $\left(\epsilon_{r} \doteq 6\right)$. The metal rod ended $1 \mathrm{~mm}$ below surface of the electrode. This configuration of electrodes ensures spatially stable filamentary discharge which is needed for CCS technique. The discharge gap was varied from $1 \mathrm{~mm}$ to $3 \mathrm{~mm}$.

The electrodes were placed in a stainless steel vacuum chamber. The system was 
evacuated by a rotary vacuum pump to approximately 1 mbar. After several minutes the pump was switched to a membrane pump and the chamber was filled either with argon (purity 99,999 vol\%) or mixture of argon and ammonia. The gas flow was kept at $100 \mathrm{sccm}$ and it was controlled by MKS 647C Multigas Controller quipped with MKS 1259CC-01000RV gas flow controller. The pressure was kept slightly above atmospheric pressure and measured by Balzers APG 011 pressure probe.

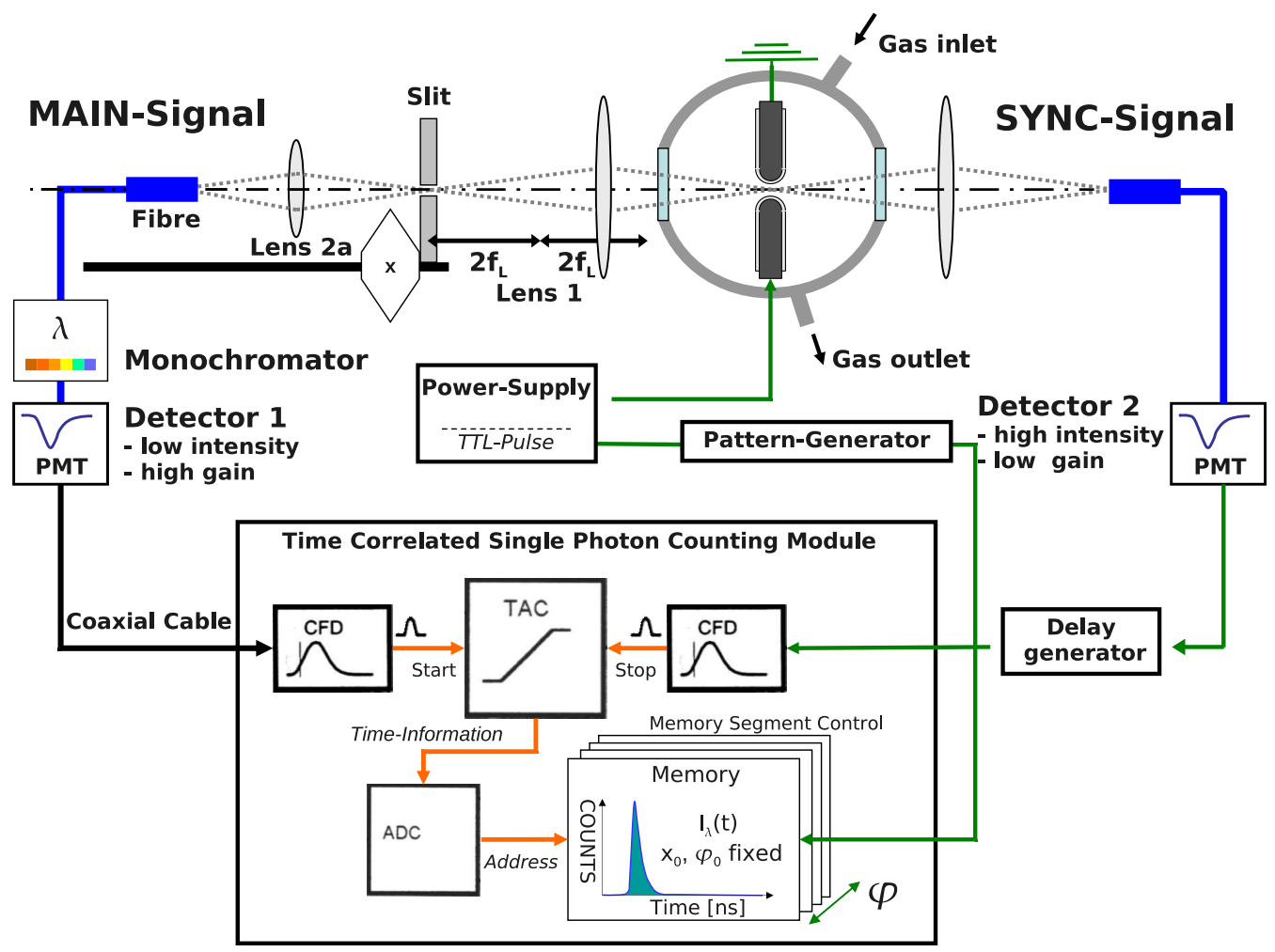

Figure 1. Experimental set-up schema.

The sinusoidal voltage at $5.2 \mathrm{kHz}$ for discharge operation was supplied by Voltcraft MXG-9802 function generator which also provided TTL pulses for synchronization. The sinusoidal voltage was then amplified by Trek PM04015A High-Voltage AC/DC Generator operated in amplifier mode. Applied high voltage was measured by Tektronix TDS3034B digital oscilloscope (300 MHz, 2.5 GSamples/s) via Tektronix P6015A 1000:1 high voltage probe. Electrical current through the discharge was measured as the voltage on $461 \Omega$ resistor connected in series with discharge cell. For this purpose Tektronix P6114B 1:10 probe was used.

The discharge chamber was equipped with two quartz windows used for CCS measurements. One window was used for MAIN signal, the second one for obtaining SYNC signal (see figure 1). In the MAIN signal path the image of the discharge image was projected onto $0.1 \mathrm{~mm}$ wide movable slit which ensured spatial resolution of the measurement. The signal was then guided with optical fibre to the input of Jobin Yvon 


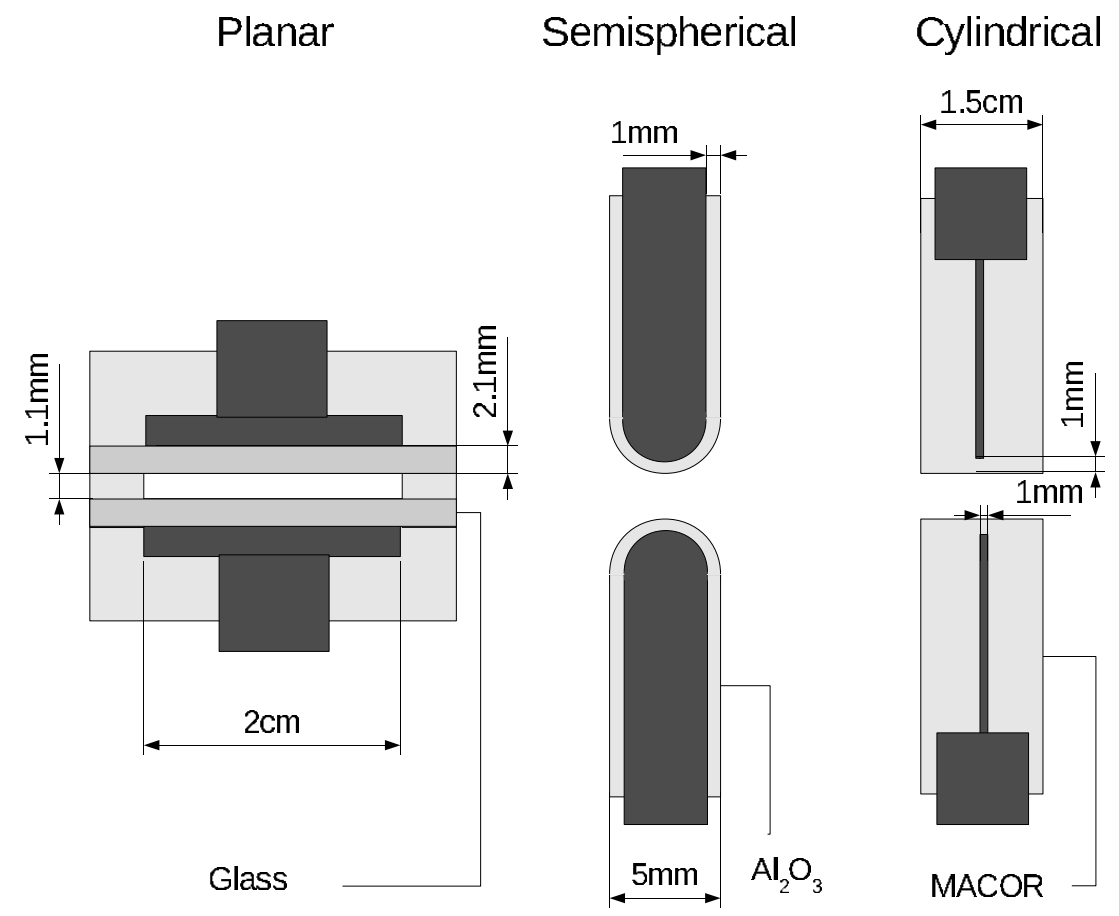

Figure 2. Electrode configuration used in experiments

Triax 320 monochromator equipped with fast PMH-100-4 photomultiplier. The signal obtained from photomultiplier was then measured by SPC-530 module. In the case of temporally unresolved overview spectra measurement the PMH-100-4 photomultiplier was replaced by Jobin Yvon DPM-HV photomultiplier. The SYNC signal (see figure 1) was sensed with PMH-100-4 for pure argon. The sensitivity of this photomultiplier was insufficient for argon/ammonia mixture so PMH-100-6 photomultiplier was used instead. Stanford Research System Inc. DG645 delay generator was inserted between photomultiplier and SPC module in order to delay the SYNC signal.

\section{Experimental results and discussion}

\subsection{Breakdown voltage in planar configuration}

Influence of ammonia on argon discharge was investigated in planar electrode configuration. Under various conditions more than one type of discharge can occur. After discharge ignition the diffuse mode can be established but after further voltage increase the discharge changes to filamentary mode. In this case the voltage at which the transition occurred is referred to as transient voltage. Since breakdown voltage is highly dependent on time since last discharge [13], the following technique was used. The applied voltage was increased until discharge appeared. The voltage was kept at this value for one minute. Then it was raised to check the existence of transient voltage. If such discharge type transition occurred, corresponding voltage was recorded. The applied voltage was then decreased until the discharge extinguished. The discharge gap 


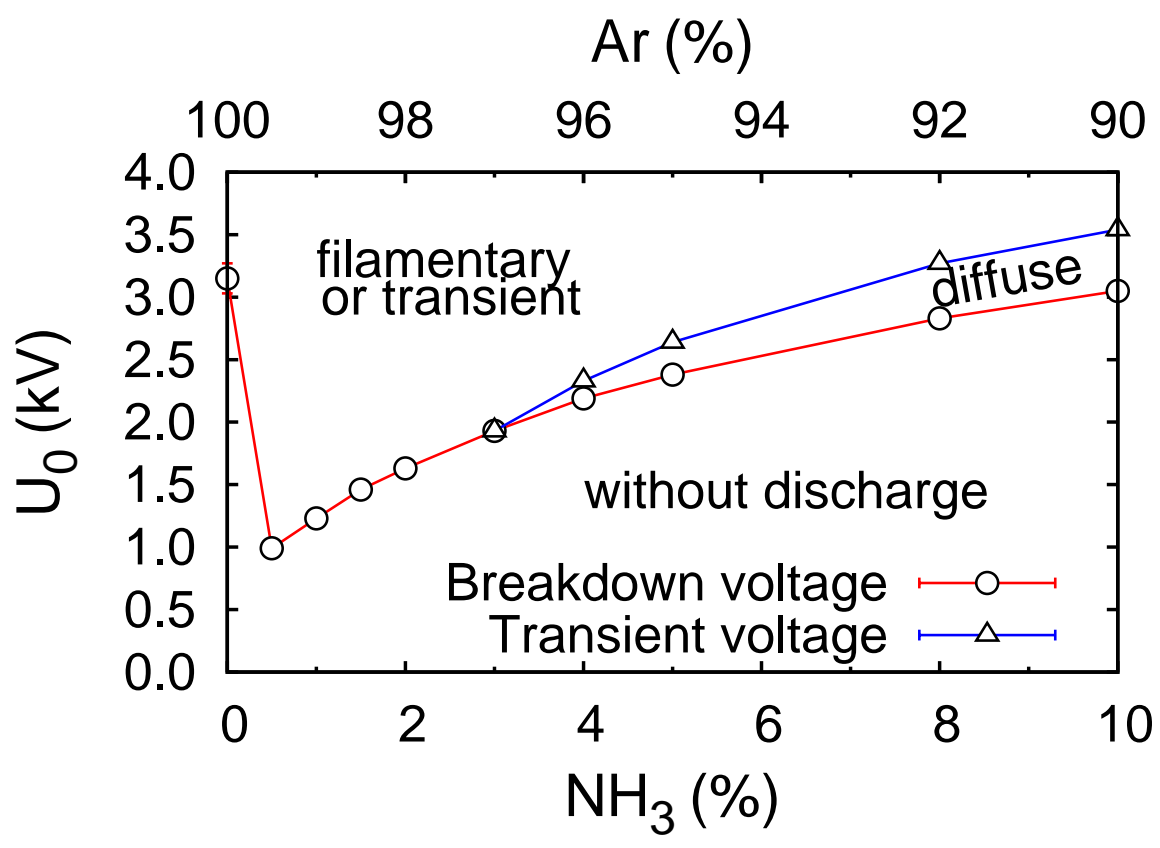

Figure 3. Breakdown voltage and transient voltage dependence on ammonia admixture. $U_{0}$ denotes amplitude of the sinusoidal applied voltage.

was then kept for one minute without discharge. Whole cycle was repeated ten times to obtain more precise results.

The influence of ammonia admixtures on breakdown voltage and transient voltage was studied for several concentrations of ammonia admixtures to argon. Obtained results, shown in figure 3, exhibit a strong influence of ammonia on breakdown voltage. Mainly small admixtures very drastically reduce the voltage required for the discharge ignition. This can be explained by Penning ionization of ammonia molecules by argon metastables. For reaction scheme of argon ammonia mixture see [10]. The diffuse discharge appears at ammonia admixture above 3 vol\%, which is different from observation reported in [10] where homogeneous glow was observed even for concentrations below $1 \mathrm{vol} \%$. The diffuse mode existence was mainly confirmed by the shape of discharge current peak as shown in figure 4 . The overall light emission decreases rapidly with increasing ammonia concentration thus it was difficult to confirm the diffuse mode by naked eye observation.

The dependence of discharge current shape on the applied voltage as well as on ammonia concentration is shown in figure 4. In the case of pure argon and small admixtures of ammonia the current oscillograms are of filamentary mode. Higher applied voltage leads to the production of higher number of filaments per halfperiod. This behaviour is consistent with standard behaviour of BD as described in [2]. With ammonia admixture higher than $3 \mathrm{vol} \%$ the response to voltage increase changes. The broad small peak representing diffuse discharge is distorted by oscillations at higher applied voltage. This behaviour is similar to that which was observed in neon or nitrogen 

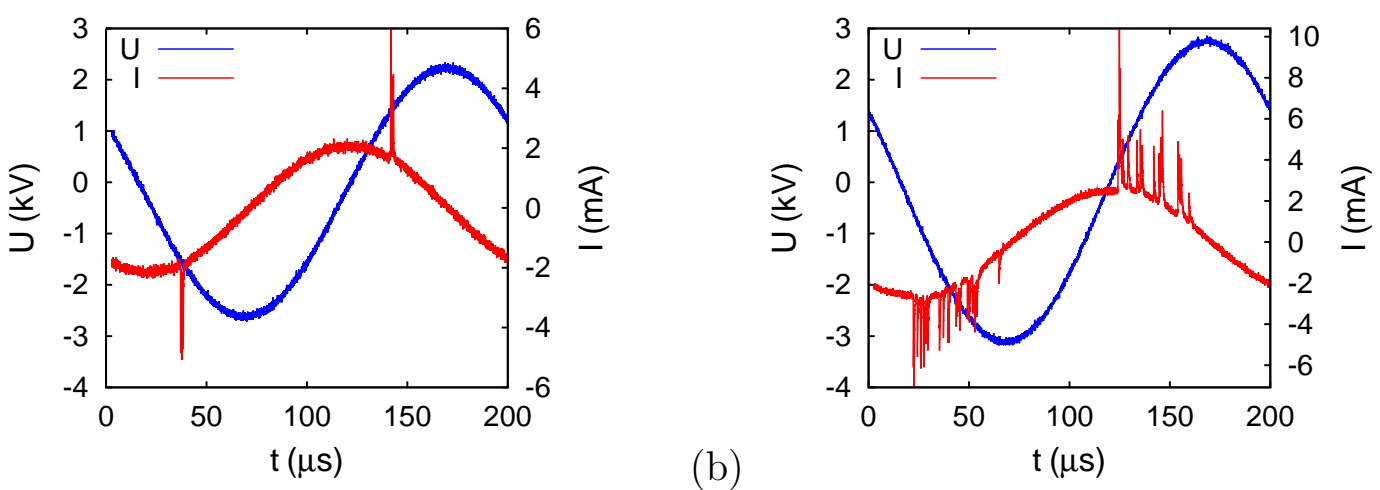

(b)
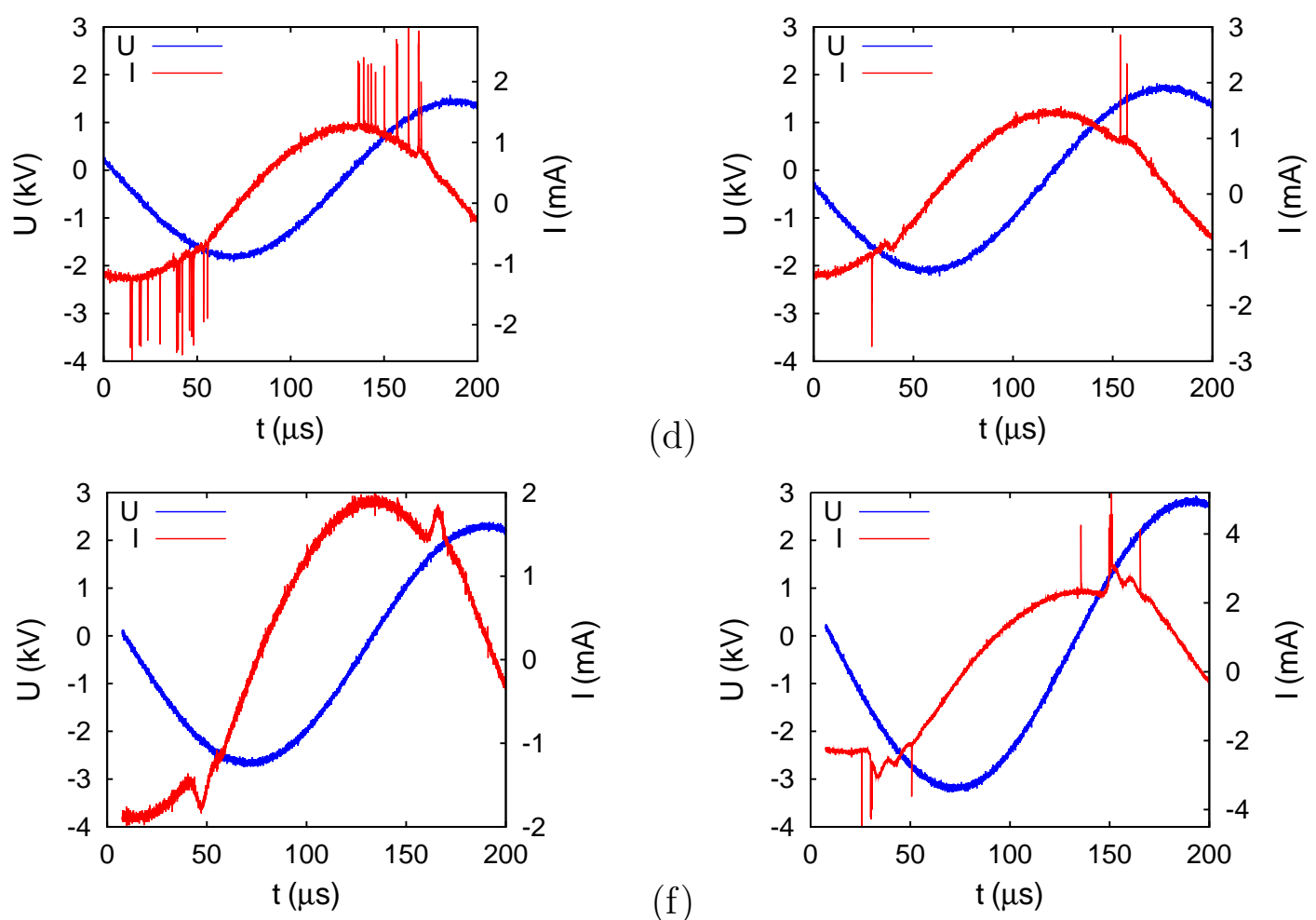

Figure 4. Electrical characteristics of discharge in pure argon and argon with small admixture of ammonia. a) pure argon, applied voltage close above breakdown voltage, b) pure argon, voltage raised to higher value than in case a), c) 2 vol\% admixture of ammonia into argon, voltage close above breakdown voltage, d) 3 vol\% admixture of ammonia to argon, applied voltage close above breakdown voltage, e) 5 vol $\%$ admixture of ammonia to argon, applied voltage close above breakdown voltage, f) 5 vol\% admixture of ammonia to argon, voltage raised to higher values than in case e). 


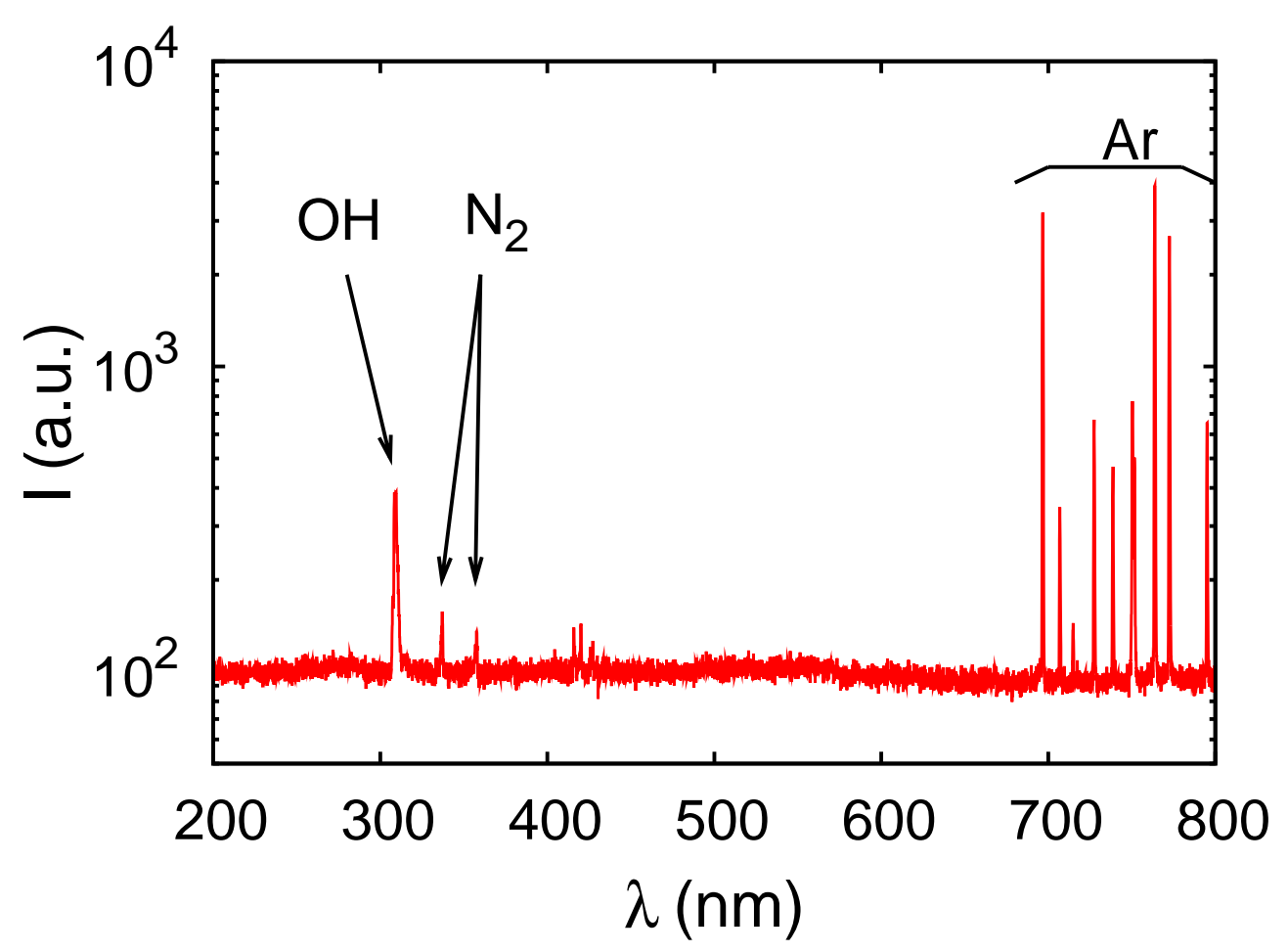

Figure 5. Spectrum of discharge in pure argon (semispherical electrodes).

[13]. Also the appearance of some filaments can be observed. The filaments were not observed directly due to weak overall light intensity from the discharge.

\subsection{Streamer development in semispherical configuration}

Semispherical electrode configuration was chosen for the study of discharge in pure argon because it provides spatially stable microdischarge required for CCS measurement. $1 \mathrm{~mm}$ gap was chosen in order to reduce the length of surface discharges which were running along the dielectric surface. The length of surface discharges can exceed the discharge gap width by order of magnitude.

The presence of impurities was checked by optical emission spectroscopy. Typical spectrum is presented in figure 5. It shows typical line structure of an argon discharge. Spectral bands belonging to nitrogen $(337.1 \mathrm{~nm})$ and $\mathrm{OH}(309.5 \mathrm{~nm})$ were observed as well. These impurities were present due to high ultimate pressure of oil rotary pump. Since their intensity distributions can serve as indicators of discharge kinetics, they were included to CCS measurements.

The results obtained from CCS measurements are presented in figure 6. It can be seen that both investigated light emissions of argon atoms exhibit the very similar pattern. The streamer appears first close to the anode and it propagates towards the cathode. After the streamer hits the cathode the discharge starts to develop. The most intensive light emission is observed close to anode. The discharge is shortly afterwards 


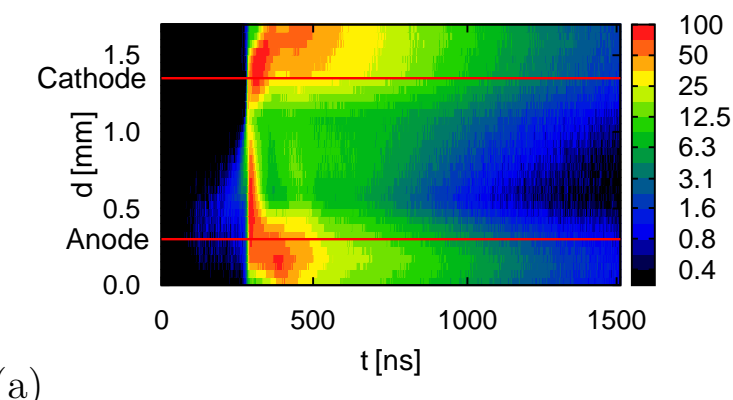

(a)

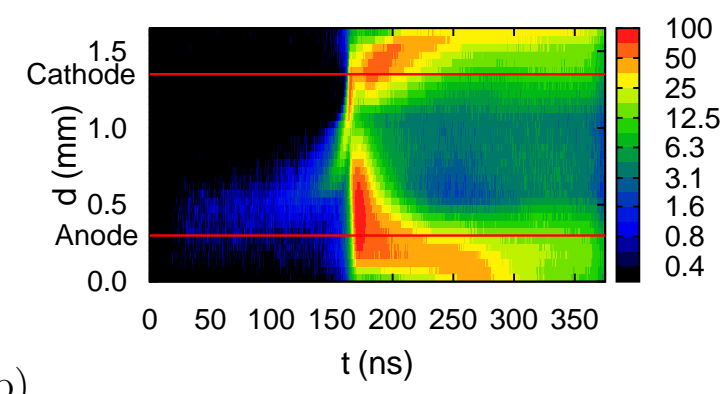

(b)
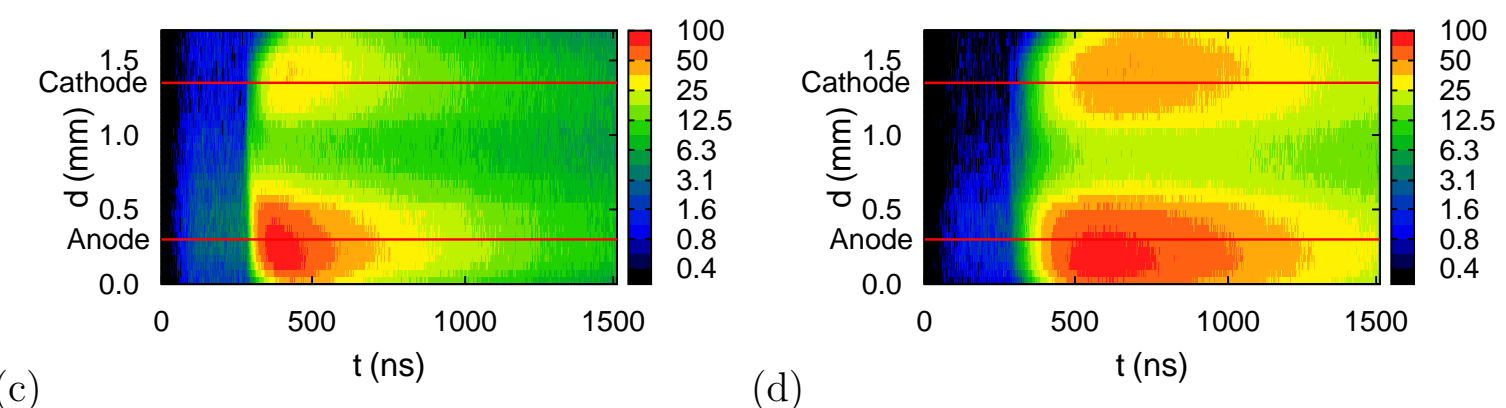

(d)

Figure 6. Results of cross correlation spectroscopy of discharge in pure argon. a) argon line $763.5 \mathrm{~nm}$; b) argon line $750.5 \mathrm{~nm}$ with higher temporal resolution. c) nitrogen emission at $337.1 \mathrm{~nm}$. d) $\mathrm{OH}$ emission at $309.5 \mathrm{~nm}$.

terminated by charge buildup on the dielectric surfaces. The long afterglow is then observed. There are also visible surface discharges which start to run from discharge gap on both electrode surfaces. At time corresponding to the start of these surface discharges a second intensity maximum is observed in the middle of the discharge gap.

Completely different distribution of light emission was observed for impurities. Neither nitrogen nor $\mathrm{OH}$ emission show streamer like pattern at the beginning of discharge. Their intensities are low at the time when streamer develops. The light emission from these impurities then starts to grow close to both electrodes with higher light intensity closer to cathode. Their emissions reach maximum intensity $100 \mathrm{~ns}$ for nitrogen and $300 \mathrm{~ns}$ for $\mathrm{OH}$ after appearance of the discharge. This behaviour indicates that impurity molecules are not excited in direct electron collisions. The excitation of impurities can thus be attributed to excitation energy transfer from excited argon atoms.

\subsection{Ammonia influence in cylindrical configuration}

When attempting to perform CCS measurement in semispherical electrode configuration we found out that the light emission was too weak in the discharge in mixture of argon with ammonia to trigger the measurement. To overcome this drawback a new pair of 
electrodes was designed. The new electrodes have the shape of dielectric cylinder with metal rod placed in the center (see figure 2). In this configuration the surface discharges did not leave the area which was observed by SYNC fiber so they could be used for measurement synchronization. Another effect was the reduction of the length of the surface discharges.

This new configuration was first tested in pure argon. The discharge gap was $2 \mathrm{~mm}$ in this experiment. The comparison of results from semispherical configuration and cylindrical configuration is shown in figure 7 . While the light emissions of impurities are unaffected by electrode change, the duration of argon light emission is reduced and no second intensity maximum in the middle of the discharge gap is observed. The difference can be attributed to the reduction of surface discharges and does not affect initial phase and streamer propagation. This is also confirmed by comparison of streamer velocity as shown in figure 8 . The streamer velocity was measured analysing the intensity development of two different argon lines for both electrode configurations. The velocity was measured using following technique. The position of maximum light emission from discharge was determined at different times. The obtained temporal dependence of position was fitted with analytical function. The sum of exponential and linear function fitted the measured data best. From the fitted analytical function the velocity was calculated. In all cases the streamer starts to propagate with the same velocity of approximately $4000 \mathrm{~m} \cdot \mathrm{s}^{-1}$ and then accelerates as it approaches the cathode. The final streamer velocity at cathode surface is the same for both configurations.

Since wider discharge gap was used for cylindrical configuration the influence of discharge gap on discharge characteristics was also investigated. Only argon lines were studied in this experiment, since development of molecular emissions remained the same (see figure 7). Obtained results are shown in figure 9. The streamer ignites in all cases at approximately the same distance from the cathode. Also the region of light emission close to anode is affected only slightly. The gap width mainly influences the duration and intensity of surface discharges. The maximum of light emission shifts from the inside of the gap to the anode surface with increasing gap width.

The ammonia influence on argon discharge was studied by optical emission spectroscopy. The observed changes were similar to [10] - appearance of NH bands, disappearance of $\mathrm{OH}$ band and decrease of argon line intensity nearly one hundred times thus highly reducing overall light intensity of the discharge. The intensity of both argon lines and NH bands decreased with increasing concentration of ammonia.

The influence of ammonia on discharge current for selected ammonia concentrations is shown in figure 10. The current peak of discharge in pure argon is identical with peaks observed in semispherical configuration. Only in case of $1 \mathrm{~mm}$ discharge gap and semispherical electrode configuration the discharge current peak exhibits second small peak at the decreasing part of current.

The CCS measurements were carried out for concentrations of ammonia of $0.1 \%$, $1.0 \%$ and $5.0 \%$. Obtained results for argon line at $763.5 \mathrm{~nm}$ are shown in figure 11. When compared to discharge in pure argon the streamer velocity is highly decreased for 

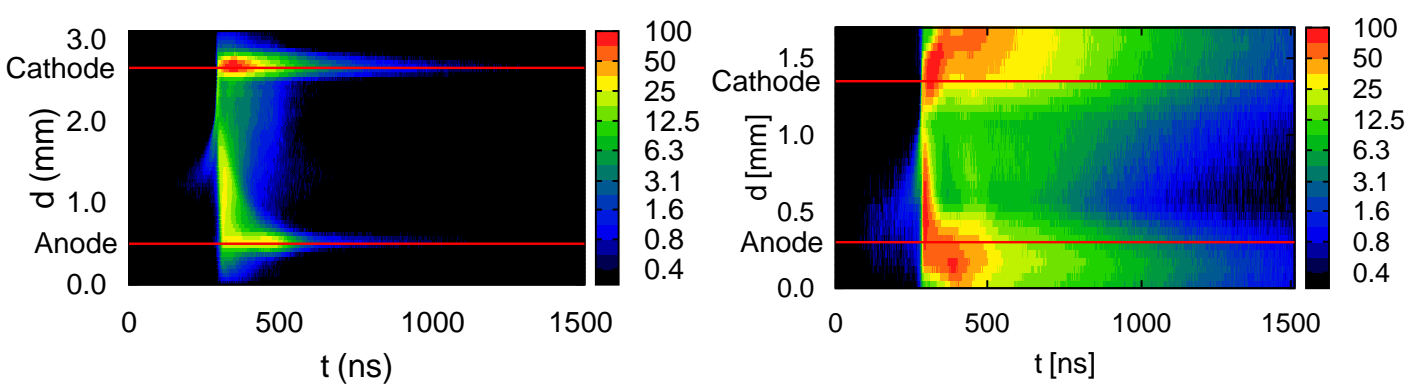

$\operatorname{Ar}(763.5 \mathrm{~nm})$
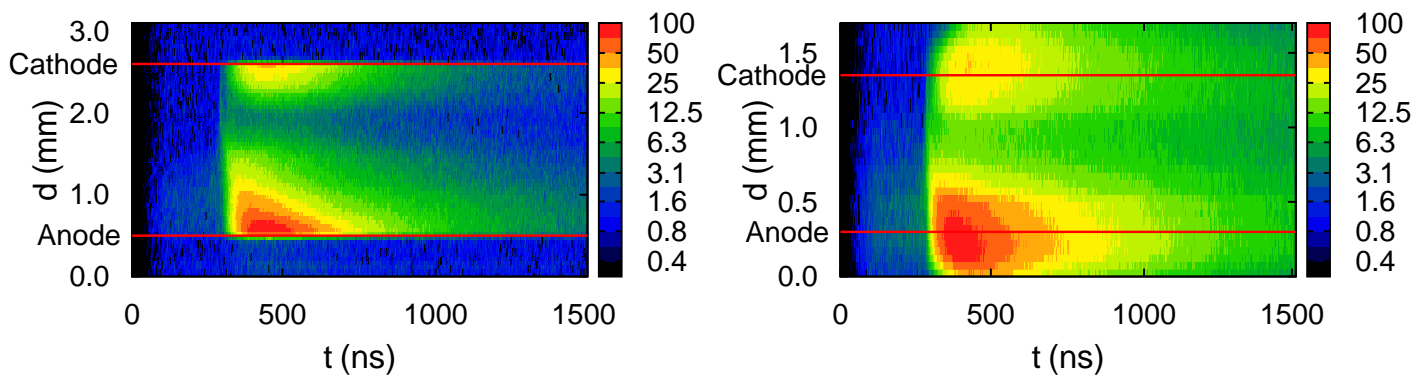

$\mathrm{N}_{2}(337.1 \mathrm{~nm})$
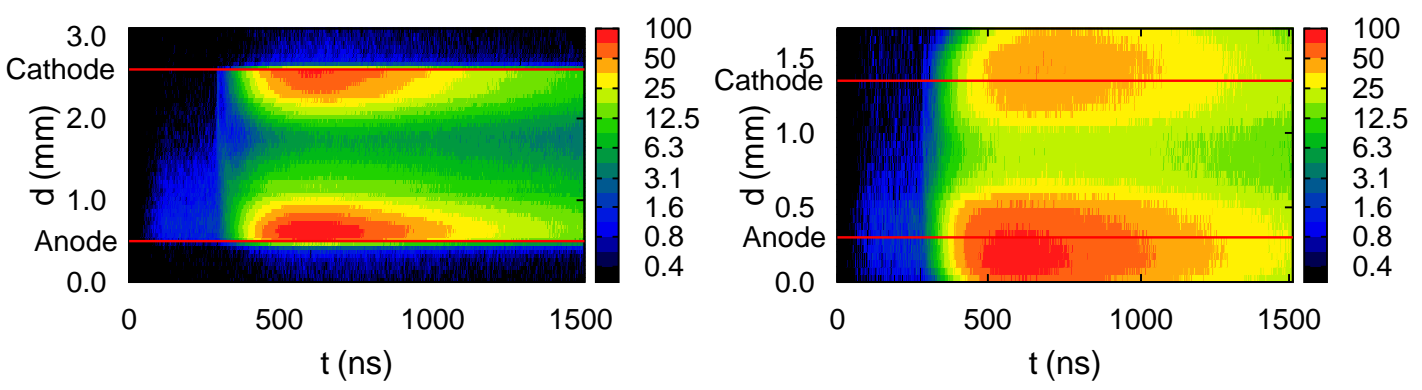

$\mathrm{OH}(309.5 \mathrm{~nm})$

Figure 7. The comparison of the discharge in pure argon in semispherical and cylindrical configuration. Left column - cylindrical configuration. Right column semispherical configuration. 


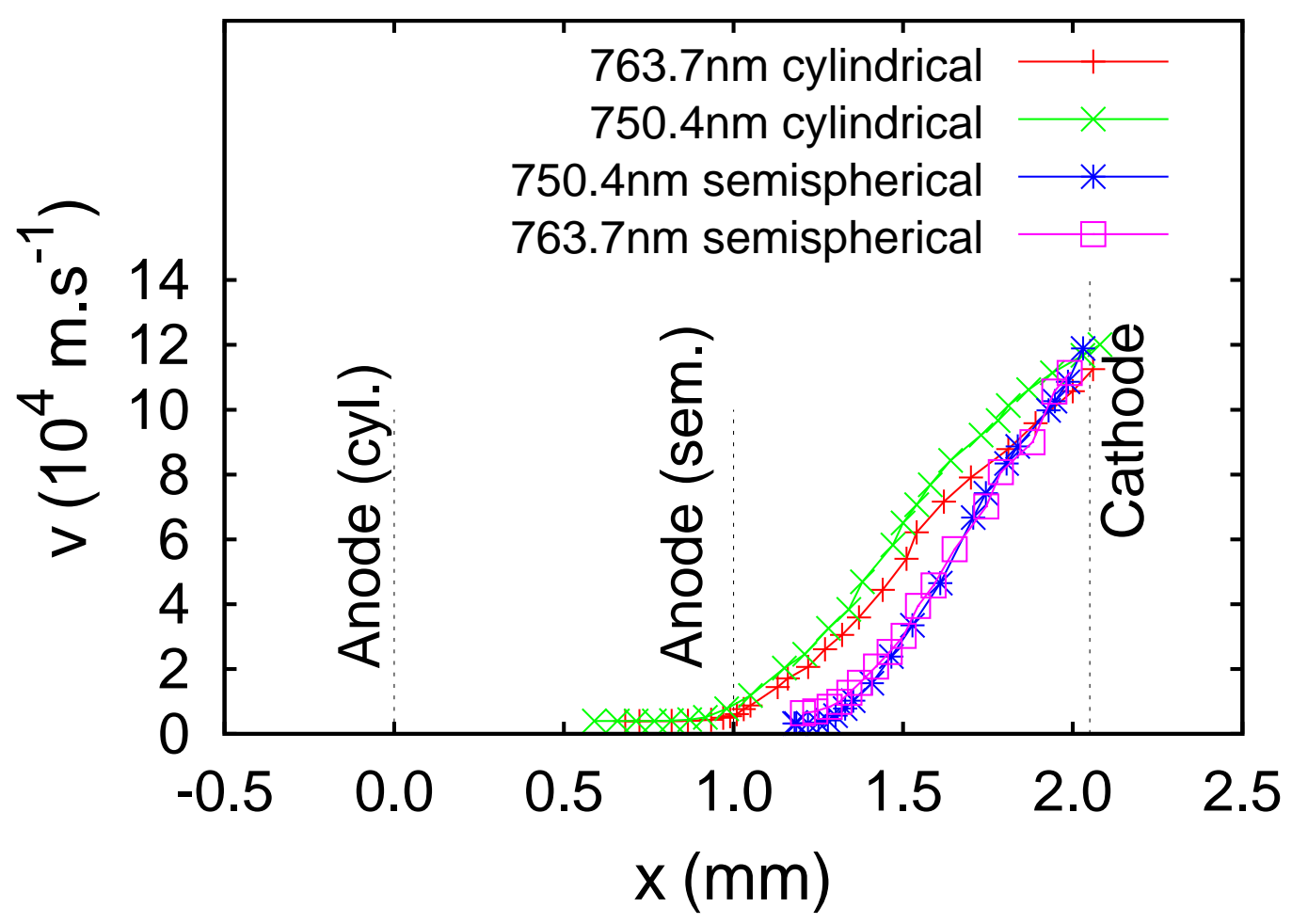

Figure 8. The dependence of the streamer velocity on distance from anode for the discharge in pure argon. The horizontal dashed lines indicate the positions of electrode surfaces.

$0.1 \%$ ammonia admixture. Such huge decrease of streamer velocity can be explained by the change in the ionization mechanism - the direct electron ionization is replaced by Penning ionization. This behaviour manifests also in the deep decrease of breakdown voltage (see figure 3). With increasing ammonia concentration the streamer velocity increases again. The strong light emission close to the anode after streamer hits cathode almost disappears after ammonia addition. Also the surface discharges are completely eliminated in the mixture. Light emission of $\mathrm{NH}$ bands exhibits the same temporal and spatial distribution as emission of argon lines.

Contrary to the measurement in planar configuration, the discharge in cylindrical configuration did not exhibit the diffuse behavior. Although the discharge channel seemed to be wider compared to discharge in pure argon, the electric current measurement did not exhibit small broad discharge peak. This behavior can probably be attributed to the electric field inhomogeneity. The electric field in cylindrical configuration is localized in the electrode axis, dropping with distance from the axis. This may prevent the discharge from spreading radially. 

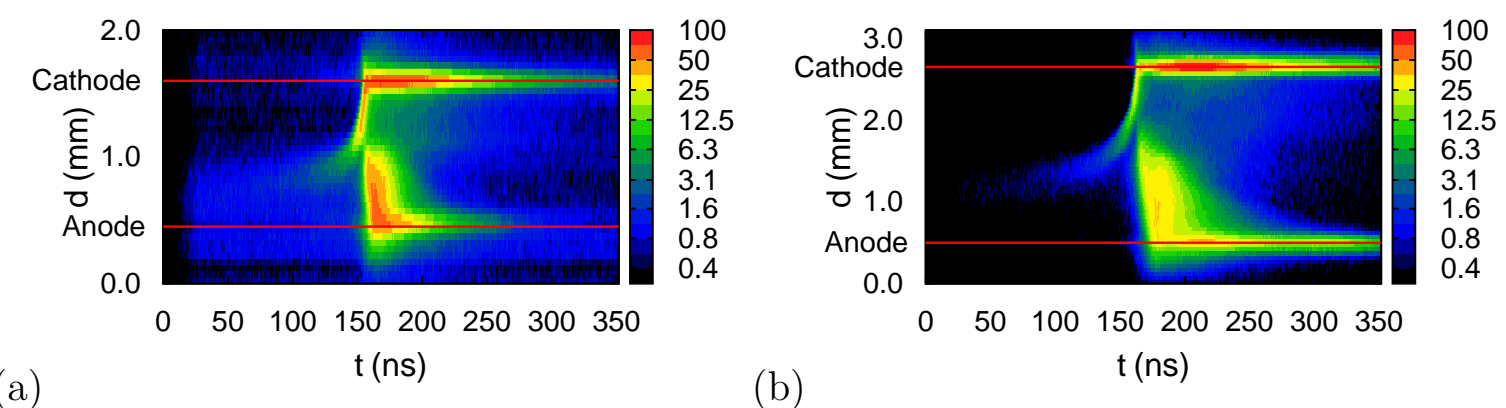

(b)

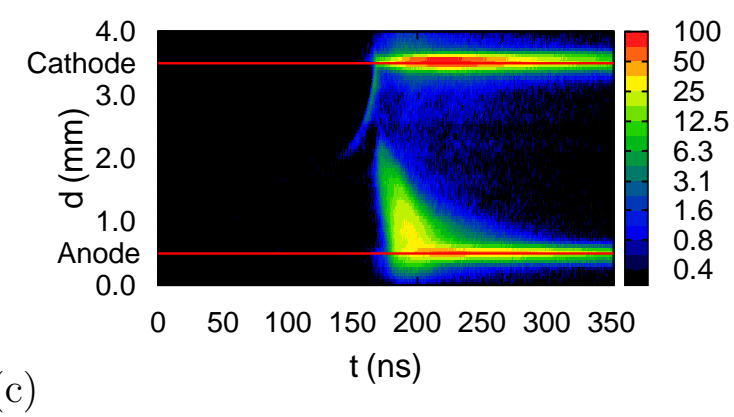

Figure 9. Influence of discharge gap on discharge in pure argon (argon line $750.5 \mathrm{~nm}$ ). a) $1 \mathrm{~mm}$ gap; b) $2 \mathrm{~mm}$ gap; c) $3 \mathrm{~mm}$ gap measured in cylindrical configuration.

\subsection{Theoretical model}

To explain the behaviour of discharge in mixture of argon with ammonia, the fully selfconsistent model is required. Some of the issues can however be addressed by simpler methods based on discharge kinetics analysis.

We solved Boltzmann equation (BE) using method described in [14] for electrons. The considered elementary processes are described in table 2 . The input cross section data for argon were obtained from $[15,16,17,18,19,20,21]$, for ammonia from [22]. Because of low frequency of applied voltage the steady-state approximation was assumed.

To evaluate the validity of our solution of BE, we calculated drift electron velocities in pure argon and pure ammonia and compared them with experimental data. This comparison is shown in figure 12. The experimental data were obtained from [23] for argon and from [22] for ammonia. The calculated drift velocity for argon fits very well the experimental data. In case of ammonia the curve does not fit well in the range $10-45 \mathrm{Td}$. This is probably due to inaccuracy of the input cross sections. Since we investigated only small admixtures of ammonia to argon, we decided to continue even with this inaccuracy.

The electron drift velocities calculated for several admixtures of ammonia to argon are presented in figure 13. Here the effect of ammonia can be clearly seen. The largest 


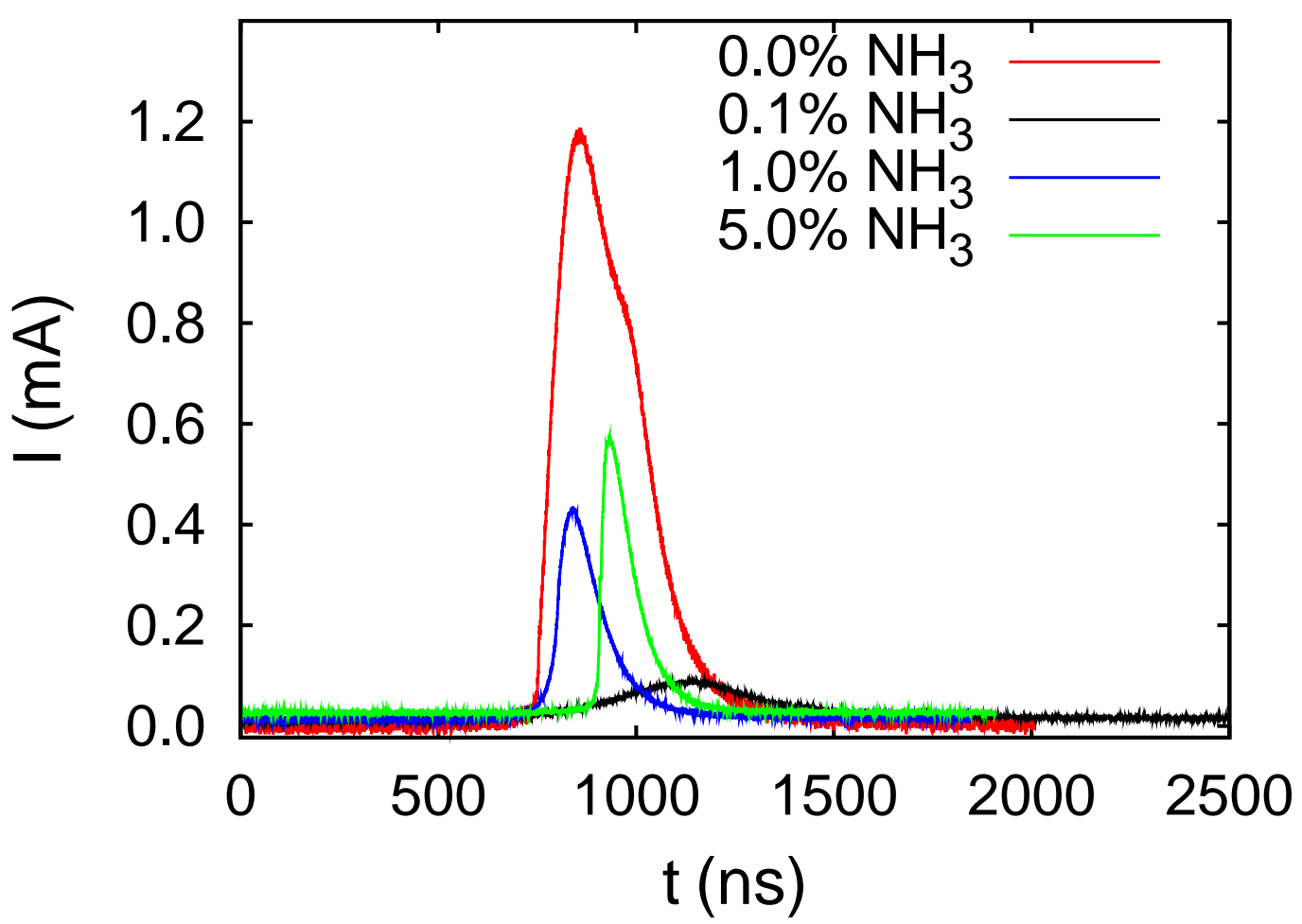

Figure 10. The comparison of discharge current peaks for different concentrations of ammonia admixture (cylindrical electrode configuration, $2 \mathrm{~mm}$ gap). The peaks are slightly shifted in time due to different trigger level.

Table 2. List of elementary processes considered in BE solving.

\begin{tabular}{ll}
\hline Elastic collision & $\mathrm{Ar}+e^{-} \rightarrow \mathrm{Ar}+e^{-}$ \\
Inelastic collisions (36 states) & $\mathrm{Ar}+e^{-} \rightarrow \mathrm{Ar}+e^{-}$ \\
Impact ionization & $\mathrm{Ar}+e^{-} \rightarrow \mathrm{Ar}^{+}+2 e^{-}$ \\
Elastic collision & $\mathrm{NH}_{3}+\mathrm{e}^{-} \rightarrow \mathrm{NH}_{3}+\mathrm{e}^{-}$ \\
Inelastic collisions (3 rotational, 4 vibrational) & $\mathrm{NH}_{3}+\mathrm{e}^{-} \rightarrow \mathrm{NH}_{3}+\mathrm{e}^{-}$ \\
Dissociative excitation & $\mathrm{NH}_{3}+e^{-} \rightarrow \mathrm{NH}+\mathrm{H}_{2}+e^{-}$ \\
Dissociative excitation & $\mathrm{NH}_{3}+e^{-} \rightarrow \mathrm{NH}_{2}+\mathrm{H}+e^{-}$ \\
Dissociative excitation & $\mathrm{NH}_{3}+e^{-} \rightarrow \mathrm{NH}^{-} 2 \mathrm{H}+e^{-}$ \\
Impact ionization & $\mathrm{NH}_{3}+\mathrm{e}^{-} \rightarrow \mathrm{NH}_{3}^{+}+2 \mathrm{e}^{-}$ \\
Electron attachment & $\mathrm{NH}_{3}+\mathrm{e}^{-} \rightarrow \mathrm{NH}_{2}^{-}+\mathrm{H}$ \\
\hline
\end{tabular}

influence of ammonia is observed for reduced electric field below $10 \mathrm{Td}$. In this region the electron drift is much higher in argon-ammonia admixture than in pure argon. At the reduced electric field values above $10 \mathrm{Td}$ the values of electron drift velocity converge to the values of argon drift velocity with increasing reduced electric field.

In CCS measurements we observed propagation of ionization wave in direction from anode to cathode. This convinced us that in argon and in mixture of argon with ammonia the discharge mechanism is driven by streamer formation. There is strong 

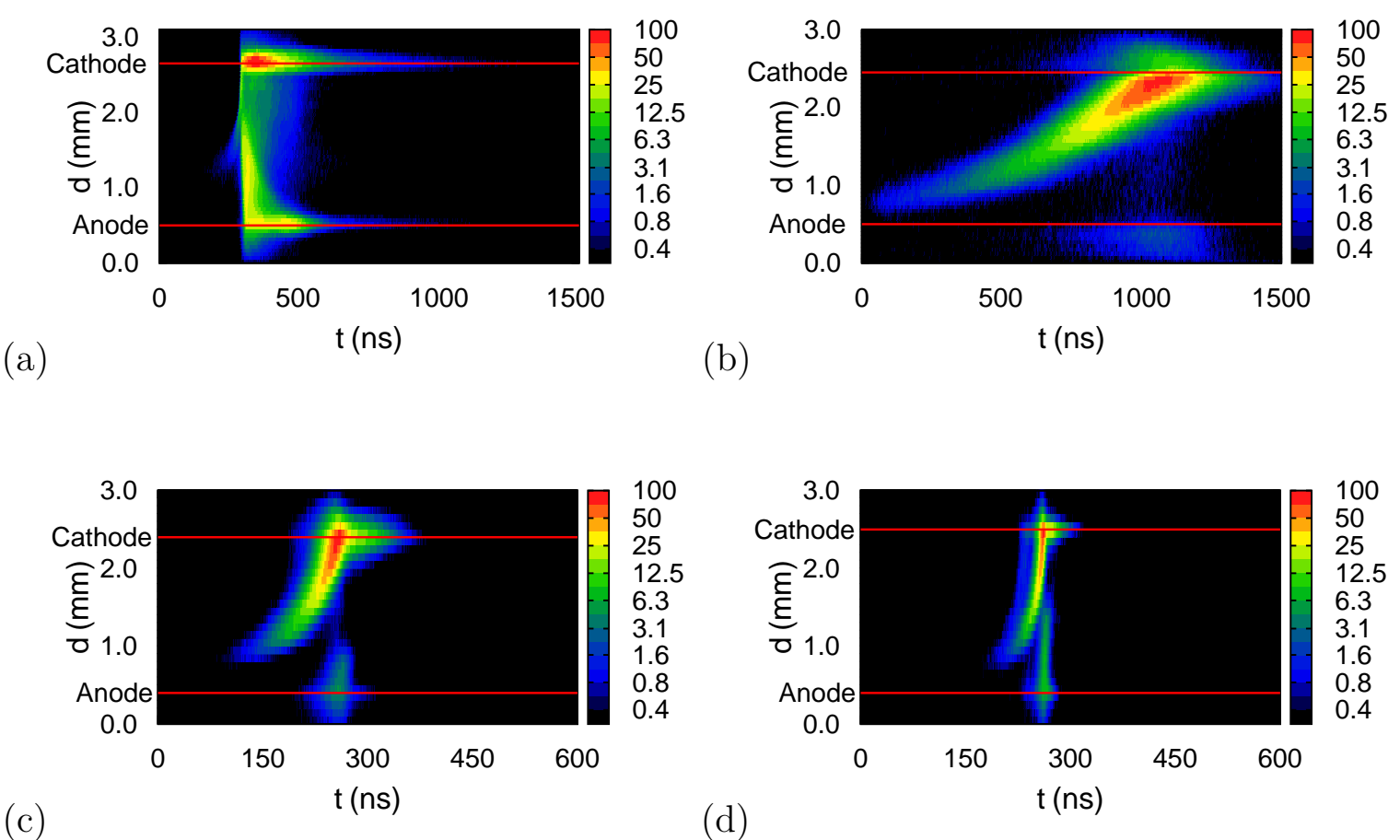

(d)

Figure 11. Influence of ammonia admixture on discharge light emission characteristics measured in cylindrical configuration. All four figures shows line at $763.5 \mathrm{~nm}$ belonging to argon. a) pure argon; b) $0.1 \%$ ammonia admixture; c) $1.0 \%$ ammonia admixture; d) $5.0 \%$ ammonia admixture. Note the different time scale of figures a), b) and c), d).

electric field at the frontal region of the streamer. But in the subsequent area the electric field is reduced by the charged particles created in frontal wave.

Ratio of diffusion coefficient and mobility is given by Einstein-Smoluchowsky relation $D / \mu=k_{b} T / e$. Due to higher electron mobility in area behind the streamer front in mixture of ammonia (see figure 13) the electrons also retain higher diffusion coefficient assuming the average electron temperature remains the same. This can lead to higher spread of electrons between the discharges and preionization in larger area. However this effect has to be confirmed by numerical simulation.

Ammonia is a molecular gas with large rotation cross sections for low energy. This causes shift of the electron energy distribution function maximum to the lower energy. This expected effect was observed in our calculations. However our calculation did not include super elastic collisions. We therefore can not qualify the full effect of ammonia on electron distribution function.

The diffuse discharge could not be produced in cylindrical electrode configuration. Even though the discharge was visibly more diffuse, no substantial change was observed in discharge current peak. The electric field in this electrode configuration is highly localized close to the axis thus creation of large area diffuse mode is not possible. 


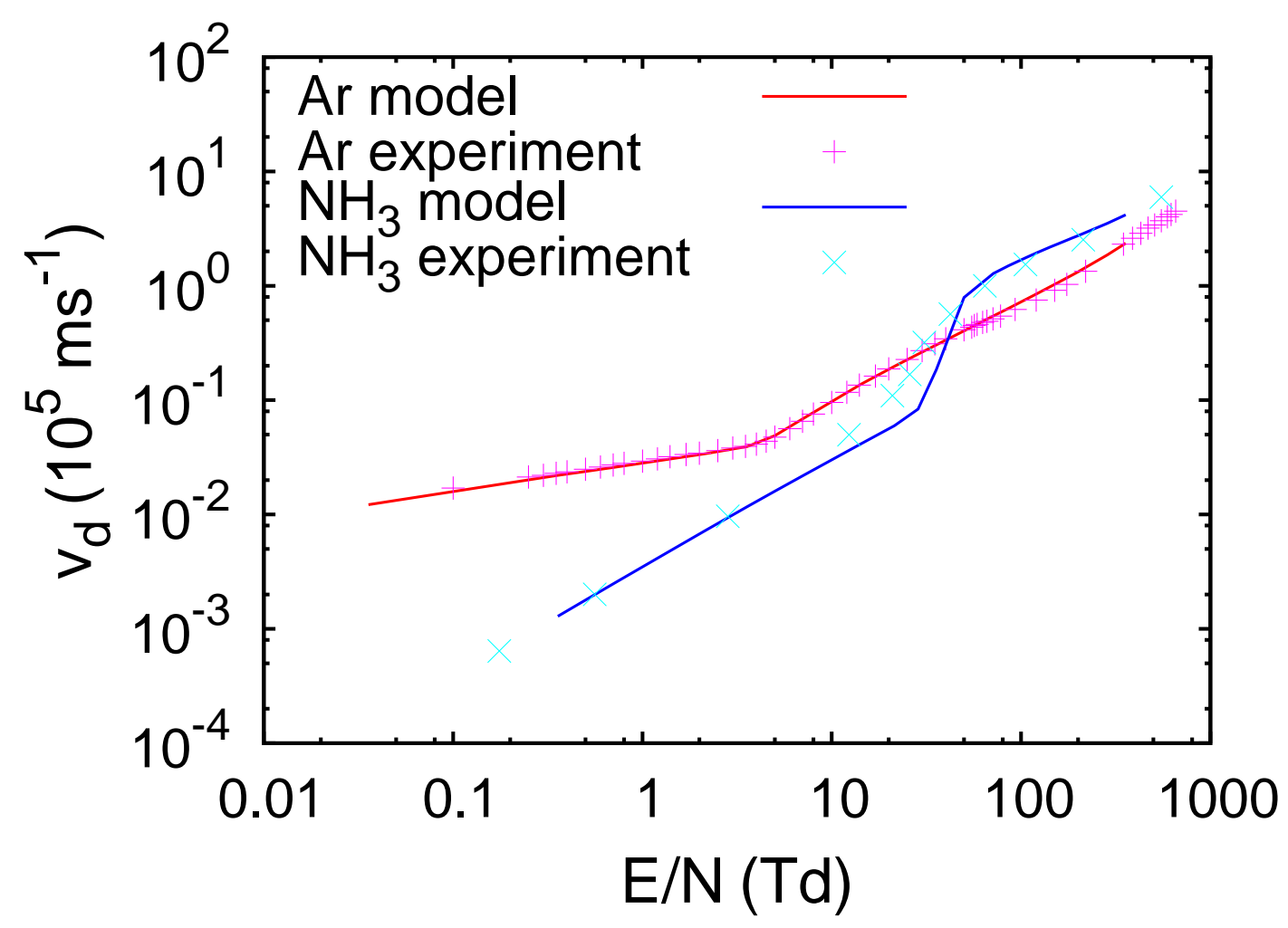

Figure 12. Comparison of calculated electron drift velocity with experimental data. The experimental data for comparison were obtained from [23] for argon and [22] for ammonia.

\section{Conclusion}

We obtained high temporally and spatially resolved spectroscopic data from discharge in argon and argon with ammonia admixture. The influence of electrode configuration on discharge in pure argon was investigated. We concluded that the influence of electrode shape is negligible in time of propagation of the streamer. The argon discharge then spreads over large surface area of electrodes. The length of this surface discharge depends on electrode configuration and it has important effect on the discharge dissipation.

The influence of ammonia admixture on discharge properties was investigated. The decrease in overall light intensity from discharge was observed. The light emission characteristics of discharge change after even a small addition of ammonia. The transition to diffuse mode was observed in case of planar electrode configuration and ammonia concentration above $3 \%$. No transition was observed in case of cylindrical electrode configuration probably due to electric field localization.

Boltzmann equation for electrons in mixture of argon with ammonia was solved. For high reduced electric field strength the drift velocity of electrons in mixture converges to that of pure argon. It was shown that for low reduced electric field strength the electrons in mixture have higher mobility and diffusion coefficient than in case of pure argon. This 


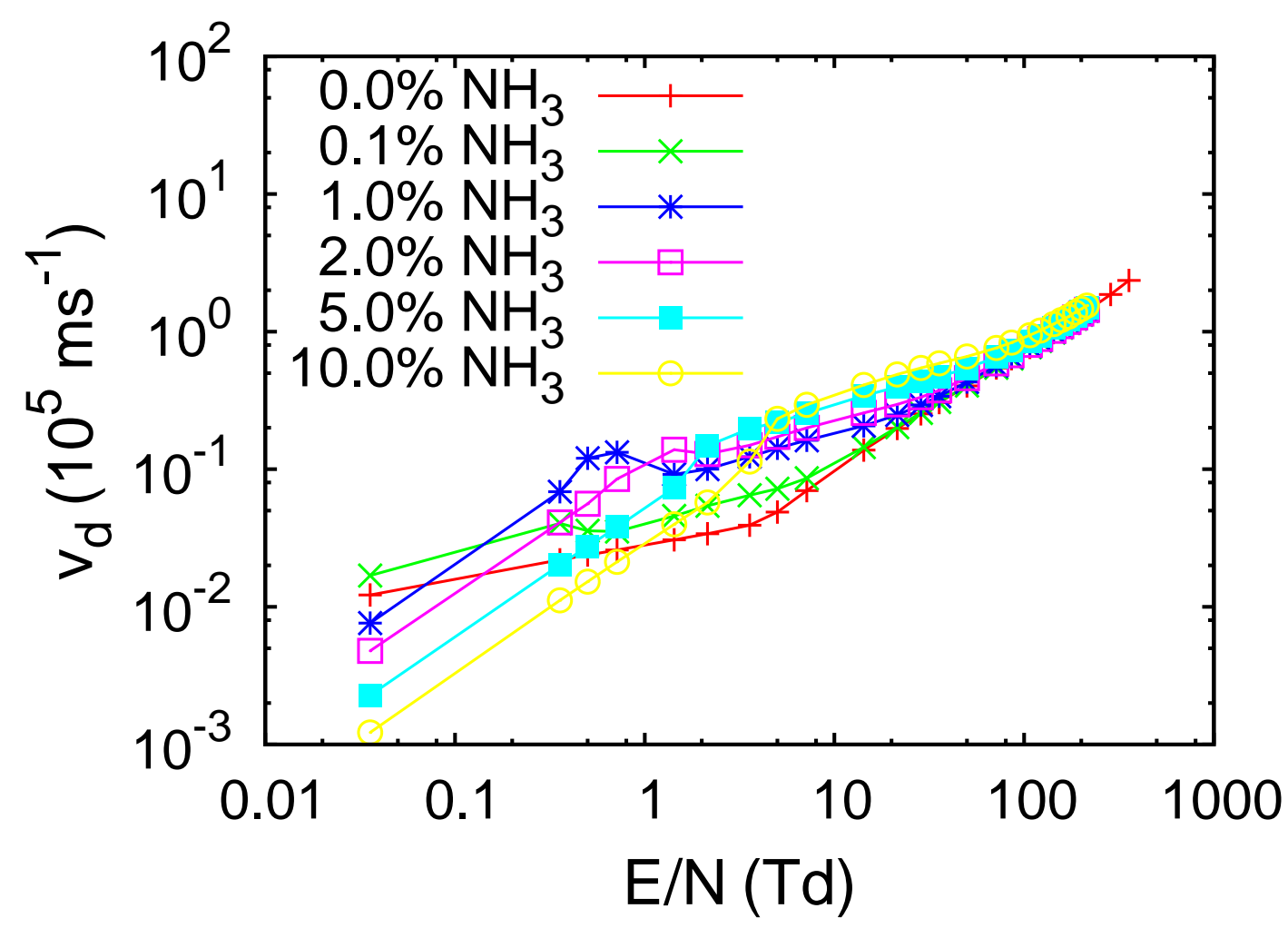

Figure 13. Electron drift velocity calculated for several concentrations of ammonia.

can positively influence the generation of the diffuse mode in argon ammonia mixture.

\section{Acknowledgments}

This work was supported by Czech Science Foundation under contract 104/09/H080 and Deutscher Akademischer Austausch Dienst (DAAD). The authors are grateful to K. V. Kozlov (Moscow State University, Department of Chemistry), T. Hoder and R. Brandenburg (Leibnitz-Institut fuer Plasmaforschung und Technologie) for their insight and opinions on covered topic.

\section{References}

[1] Kogelschatz U 2002 IEEE Trans. Plas. Sci 30 1400-8

[2] Kogelschatz U, Eliasson B and Egli W 1997 Proceedings Phen. Ion. Gas. ICPIG (Toulose)

[3] Massines F, Gherardi N, Naude N and Segur P 2009 Eur. Phys. J. - Appl. Phys. 4722805

[4] Brandenburg R, Maiorov V A, Golubovskii Yu B, Wagner H-E, Behnke J and Behnke J F 2005 J. Phys. D: Appl. Phys. 38 2187-97

[5] Kozlov K V, Brandenburg R, Wagner H-E, Morozov A M and Michel P 2005 J. Phys. D: Appl. Phys. 38 518-29

[6] Trunec D, Brablec A and Buchta J 2001 J. Phys. D: Appl. Phys. 34 1697-99

[7] Massines F, Rabehi A, Decomps P, Gadri R B, Segur P and Mayoux C 1998 J. Appl. Phys. 83 $2950-7$ 
[8] Navratil Z, Brandenburg R, Trunec D, Brablec A, Stahel P, Wagner H-E and Kopecky Z 2006 Plasma Sources Sci. Technol. 15 8-17

[9] Kozlov K V and Wagner H-E 2007 Contrib. Plasma Physics 47 26-33

[10] Fateev A, Leipold F, Kusano Y, Stenum B, Tsakadze E and Bindslev H 2005 Plasma Processes and Polymers 2 193-200

[11] Lieberman M A and Lichtenberg A J 1994 Principles of Plasma Discharges and Material Processing (New York: John Wiley \& Sons)

[12] Kozlov K V, Wagner H-E, Brandenburg R and Michel P 2001 J. Phys. D: Appl. Phys. 34 3164-76

[13] Brandenburg R, Navratil Z, Jansky J, Stahel P, Trunec D and Wagner H-E 2009 J. Phys. D: Appl. Phys. 42085209

[14] Hagelaar G J M and Pitchford L C 2005 Plasma Sources Sci. Technol. 14 722-33

[15] Yamabe C, Buckman S J and Phelps A V 1983 Phys. Rev. A 27 1345-52

[16] Khakoo M A, Vandeventer P, Childers J G, Kanik I, Fontes C J, Bartschat K, Zeman V, Madison D H, Saxena S, Srivastava R and Stauffer A D 2004 J. Phys. B: At. Mol. Phys. 37 247-81

[17] Chiltin J E, Boffard J B, Schappe R S and Lin C C 1998 Phys. Rev. A 57 267-77

[18] Hayashi M 2003 Bibliography of Electron and Photon Cross-Sections with Atoms and Molecules Published in the 20th Century - Argon (Tokyo: National Institute for Fusion Science)

[19] Weber T, Boffaed J B and Lin C C 2003 Phys. Rev. A 68 32719-30

[20] Drawin H W 1967 Report EUR-CEA-FC-383 (Association Euroatom-CEA)

[21] Rapp D and Englander-Golden P 1965 J. Chem. Phys. 43 1464-79

[22] Yousfi M and Benabdessadok M D 1996 J. Appl. Phys. 80 6619-30

[23] Ellis H W, Pai R Y, McDaniel E W, Mason E A and Viehland L A 1976 Atomic Data and Molecular Data Tables 17177 